\title{
RESEARCH ON MORPHOLOGY AND DIAMETER OF NON-METALLIC INCLUSIONS IN ANALYZED STEELS
}

\author{
${ }^{1}$ Marek WARZECHA, ${ }^{2}$ Tomasz MERDER, ${ }^{1}$ Artur HUTNY, ${ }^{3}$ Łukasz ROGAL \\ ${ }^{1}$ Czestochowa University of Technology, Faculty of Production Engineering and Materials Technology, \\ Czestochowa, Poland, EU, warzecha@wip.pcz.pl \\ 2 Silesian University of Technology, Faculty of Materials Engineering and Metallurgy, Katowice, Poland, EU, \\ tomasz.merder@polsl.pl \\ ${ }^{3}$ Institute of Metallurgy and Materials Science of Polish Academy of Sciences, Cracow, Poland, EU \\ https://doi.org/10.37904/metal.2019.793
}

\begin{abstract}
Quantitative methods for determining the contamination of non-metallic inclusions (NMI) steel can be divided into metallographic, physicochemical or chemical. The quality control of steel in the metallurgical industry mostly uses a method in which their microstructure is observed on undigested destruction. In this way, the initial morphological characteristics of the NMI are revealed and their quantity, size and distribution can be estimated.

Presented work is a part of a larger project investigation on the distribution of non-metallic inclusions in liquid steel, carried out using both: physical and numerical modelling research techniques. Therefore, before performing the model investigations, determinations were made, including the disclosure of the inclusions morphology occurring in the steels along with their diameters.
\end{abstract}

Keywords: Non-metallic inclusions, steel, tundish, metallographic analysis

\section{INTRODUCTION}

Non-metallic inclusions in steels occur as a consequence of technologies being used and the type of batch materials. Non-metallic inclusions arise primary:

- $\quad$ as liquid steel deoxidation and desulfurization products,

- during casting and solidification of liquid steel, as a result of the temperature drops - due to an increase in the standard enthalpy formation and solubility drop of steel components in the solid phase,

- $\quad$ as a consequence of steel contamination with particles of refractory lining, slag and non-metallic precipitates that originate from the synthesis of alloy additive components, being introduced into the liquid steel [1-6].

None of the modern metallurgical methods allows for producing steel as a pure product free of any inclusions. One of the capabilities is to limit the number of supercritical and critical non-metallic inclusions. The presence of $\mathrm{NMI}$ in an ingot causes defects during plastic forming processes and damage to finished products in the time of their later usage. Therefore, it is desirable to reduce the content of inclusions in steel during its production. Rising quality requirements force constant reduction - in terms of size and number - of inclusions in steels. Thus, the behaviour of non-metallic inclusions (NMI) in the liquid (liquid steel) during the casting process is an important factor $[2,6]$.

This research paper presents results demonstrating strict structure of the NMI distribution in samples of steel collected in tundish during production cycle. Results of the presented tests are a part of a larger research work [7] concerning research tests on distribution of non-metallic inclusions in the liquid steel, carried out by using two research techniques, namely the physical and numerical modelling analyses. Aim of these tests was to facilitate selection of proper microparticles for model tests and to define conditions in mathematical model and 
numerical problem solving model with the CFD (Computational Fluid Dynamics) technique. Preliminary results of these tests are presented in the work [8].

\section{QUALITATIVE AND QUANTITATIVE ASSESSMENT METHODS OF THE MICROSTRUCTURE}

The research tests, which aimed at the analysis of the so-called phase steel purity (share, quantity and size) were carried out on 15 samples -,lollipops" - taken from the melts of twelve different grades (low-, medium-, high-carbon and micro-alloys) of steel. Sampling was performed during smelting (normal production cycle) in tundish. Sampling plan is shown in Figure 1.

a)

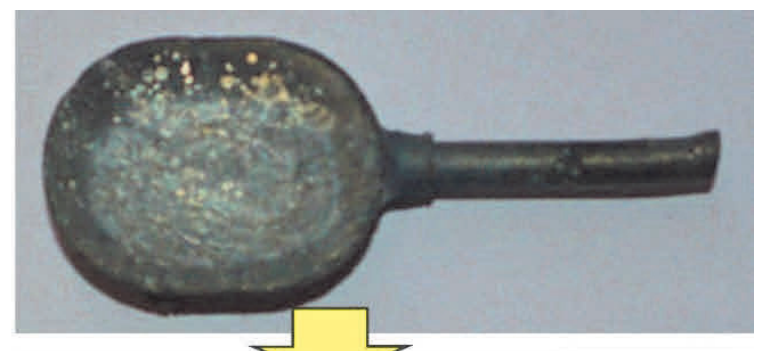

b)

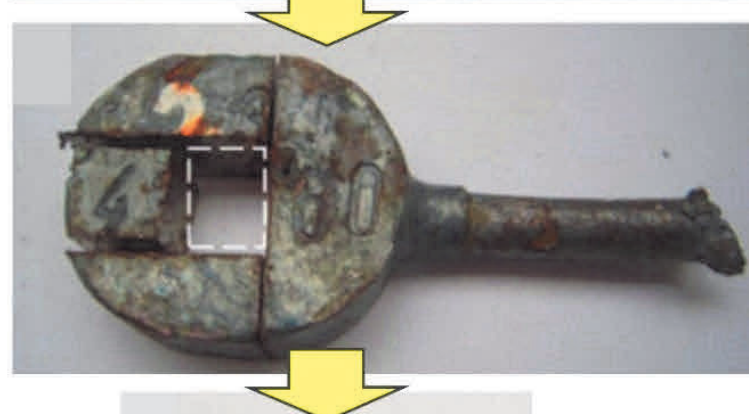

c)

d)
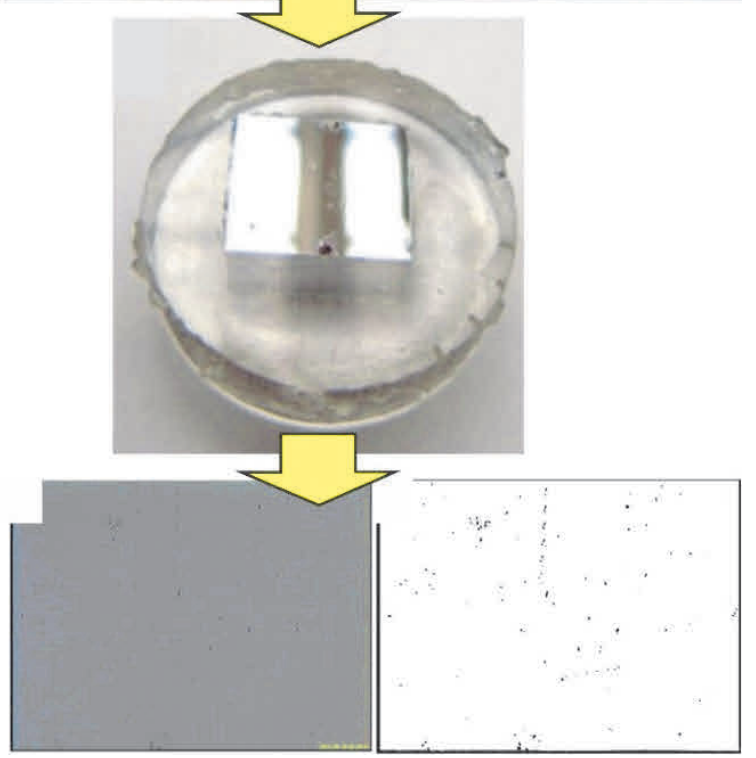

Figure 1 Sampling plan for testing with an exemplary microstructure
A section (in the size of $1.5 \times 1.5 \mathrm{~cm}$ ) was taken from each sample (Figure 1a) in order to prepare a microsection. Place and method of collecting the fraction (was marked with a broken line) (Figure 1b) from a lollipop sample. Then, the sample being cut off was embedded in the resin (Figure 1c). Metallographic specimens were prepared according to the following procedure: grinding on abrasive papers with gradation 80 1200 , polishing by using felts with addition of diamond pastes. The microsections were not subject to digestion. The same procedure was used for all samples.

Surface micro-images taken from samples, being prepared by using the abovementioned method, were recorded by using optical microscope (Leica DM IRM) [9] equipped with camera that enabled digital image recording (JVC TK-C1380) [10] (Figure 2). The record was made from neighbouring areas (from 35 to 40 for each sample). Twenty photos of microstructure for each sample were subject to the digital image analysis. The analysis consisted of: setting up the scale for photos (according to the scale recorded at the same magnification of the microscope 1000x), image conversion to an 8-bit-image, determining the colour threshold, which was a boundary limit to analyse particles, manual correction (for example: separation of particles that have merged into one at the time of establishing the threshold, removing from the image "false particles" - which were created - for example - on the lineament remained after sample preparation, etc.). An example of a registered image is shown in Figure 1d.

Shape coefficient (NMI) was calculated according to the formula:

$$
K_{c}=4 \cdot \pi \cdot A / B^{2}
$$

where: $A$ - surface area of inclusion, $B$ - circumference of inclusion. 
So defined shape factor adopts values within the range of $\langle 0 \div 1\rangle$. Higher values in this range mean spherical shape. Values below 1 define the so-called globular shape. Representative average particle size is the diameter calculated directly from the surface area of the circle.

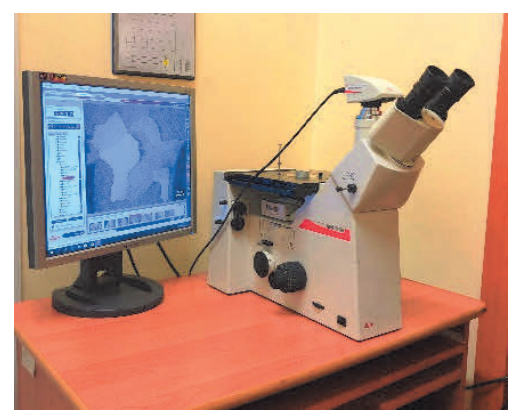

Figure 2 View of the research stand

\section{TEST RESULTS}

Detailed results of the performed analyses for the selected sample (A) are presented in Table 1.

Table 1 Test results for the sample A

\begin{tabular}{|c|c|c|c|c|c|c|}
\hline No. & $\begin{array}{l}\text { Number of } \\
\text { records }\end{array}$ & $\begin{array}{c}\text { Total } \\
\text { measuring } \\
\text { area, } \\
\left(\mu \mathrm{m}^{2}\right)\end{array}$ & $\begin{array}{c}\text { Average area of } \\
\text { inclusions, } \\
\left(\mu \mathrm{m}^{2}\right)\end{array}$ & $\begin{array}{c}\text { Participation, } \\
\text { (\%) }\end{array}$ & $\begin{array}{l}\text { Coefficient } \\
\text { shape }\end{array}$ & $\begin{array}{c}\text { Average } \\
\text { size of NMI } \\
d,(\mu \mathrm{m})\end{array}$ \\
\hline 1 & 547 & 470.91 & 0.86 & 0.94 & 0.90 & 1.05 \\
\hline 2 & 151 & 147.14 & 0.97 & 0.29 & 0.87 & 1.11 \\
\hline 3 & 196 & 234.57 & 1.20 & 0.47 & 0.88 & 1.24 \\
\hline 4 & 130 & 139.27 & 1.07 & 0.28 & 0.91 & 1.17 \\
\hline 5 & 111 & 145.74 & 1.31 & 0.29 & 0.86 & 1.29 \\
\hline 6 & 134 & 230.82 & 1.72 & 0.46 & 0.84 & 1.48 \\
\hline 7 & 163 & 165.92 & 1.02 & 0.33 & 0.90 & 1.14 \\
\hline 8 & 153 & 205.83 & 1.35 & 0.41 & 0.89 & 1.31 \\
\hline 9 & 141 & 174.99 & 1.24 & 0.35 & 0.89 & 1.26 \\
\hline 10 & 144 & 157.61 & 1.09 & 0.32 & 0.89 & 1.18 \\
\hline 11 & 139 & 124.68 & 0.90 & 0.25 & 0.89 & 1.07 \\
\hline 12 & 177 & 235.90 & 1.33 & 0.47 & 0.87 & 1.30 \\
\hline 13 & 116 & 178.61 & 1.54 & 0.36 & 0.88 & 1.40 \\
\hline 14 & 88 & 149.99 & 1.70 & 0.30 & 0.85 & 1.47 \\
\hline 15 & 138 & 244.72 & 1.77 & 0.49 & 0.84 & 1.50 \\
\hline 16 & 194 & 246.81 & 1.27 & 0.49 & 0.85 & 1.27 \\
\hline 17 & 174 & 297.83 & 1.71 & 0.60 & 0.87 & 1.48 \\
\hline 18 & 143 & 228.48 & 1.60 & 0.46 & 0.85 & 1.43 \\
\hline 19 & 118 & 141.81 & 1.20 & 0.28 & 0.87 & 1.24 \\
\hline 20 & 118 & 134.26 & 1.14 & 0.27 & 0.86 & 1.20 \\
\hline Average & 163.75 & 202.79 & 1.30 & 0.41 & 0.87 & 1.28 \\
\hline
\end{tabular}


Sample graph of the average surface area analysis and the NMI shape factor for a sample (sample B) is indicated in Figure 3.
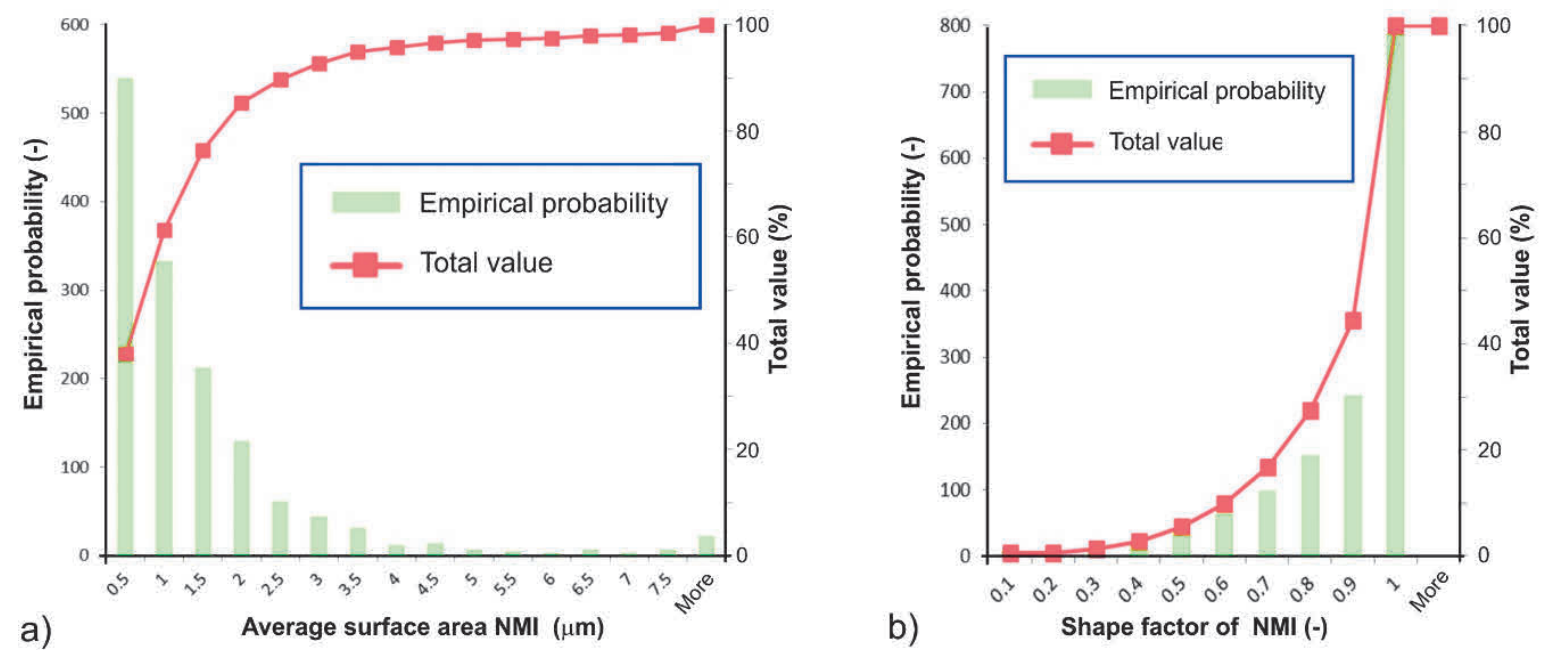

Figure 3 Histogram for characteristic of B sample: a) an average surface area of non-metallic inclusions, b) shape factor of non-metallic inclusions

Following analysed characteristics of inclusions for all of the 15 samples are as follows: the NMI shape factor, the NMI average dimension, average surface are of the NMI and their surface share (which -in simplified terms - reflects the volume share). Subsequent values of the mentioned parameters are shown in Figure 4.

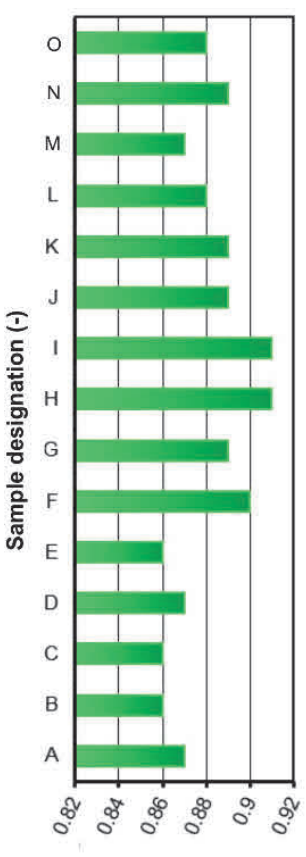

Shape factor (-)

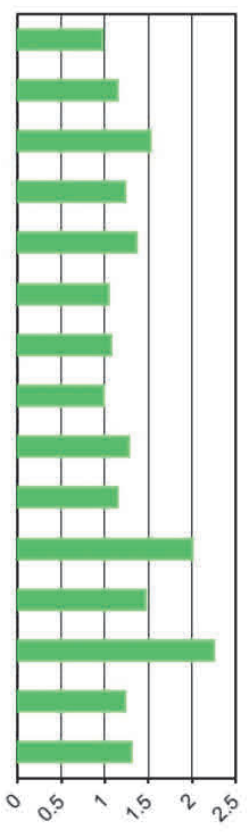

Average surface area of NMI $\left(\mu \mathrm{m}^{2}\right)$

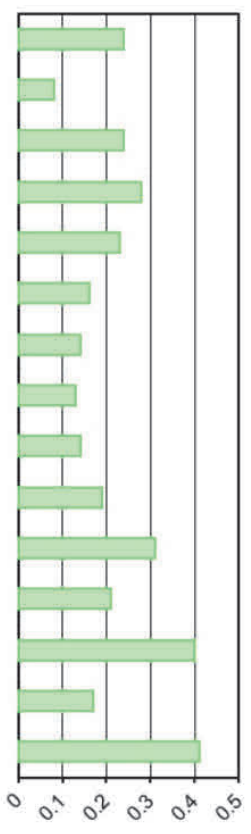

NMI participation (\%)

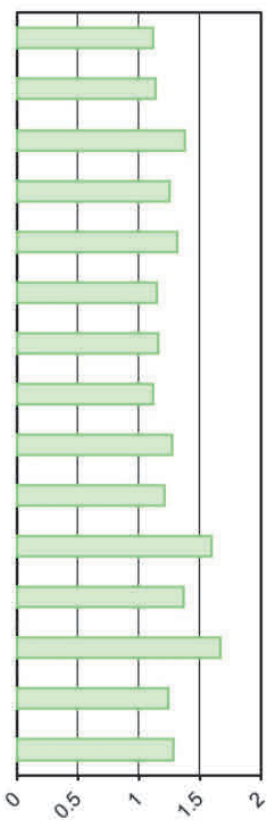

Average size of NMI $(\mu \mathrm{m})$

Figure 4 Test results for 15 samples

The analysis of the presented results in (Figure 4) clearly indicates that in the collected samples, the surface share of NMI is within the range of $\langle 0.08 \div 0.41\rangle \%$. The NMI shape factor receiving the value of $\langle 0.86 \div 0.91\rangle$ 
is close to unity. The average surface area of NMI in the samples contains in the range of $\langle 0.97 \div 2.25\rangle \mu \mathrm{m}^{2}$, while the average size of NMI does not exceed the value of $5 \mu \mathrm{m}$. Larger sizes are very rare - they are most likely the result of poorly performed deoxidation or exogenous inclusion - micro-fragments of the tundish refractory lining or a microparticle of slag drawn from the surface of the liquid steel, and so on.

\section{CONCLUSIONS}

Based on the performed research tests, following conclusions can be stated, namely:

- The shape factor NMI $\langle 0.86 \div 0.91\rangle$ is close to unity, which allows to make the assumption that they are close to globular.

- The surface share of NMI is in the range of $\langle 0.08 \div 0.41\rangle \%$.

- $\quad$ The average NMI value does not exceed $5 \mu \mathrm{m}$. Larger sizes are very uncommon.

- The average surface area of NMI in samples ranges between $\langle 0.97 \div 2.25\rangle \mu^{2}$.

Marked shape factor, which is close to unity is the most important finding of the conducted research tests. Determination of this parameter is of great importance from the point of view of the planned NMI distribution tests being performed in liquid steel by using two research techniques, namely the physical and numerical modelling. It is crucial in selecting microparticles for model research tests and defining conditions in a mathematical model, as well as, in solving numerically the problem with the CFD technique.

\section{ACKNOWLEDGEMENTS}

This paper was created with the financial support of the Project No. 2013/09/b/st8/00143. Project funded by the National Science Centre of the Poland (from which the researches was carried out).

\section{REFERENCES}

[1] LIS, Teresa. Metallurgy of ultra-clean steel. Gliwice: Publishing of the Silesian University of Technology, 2009. p. 192.

[2] THOMAS, B.G., YUAN, Q., ZHANG, L., VANKA, S.P., Flow dynamics and inclusion transport in continuous casting of steel. Service and Manufacturing Grantees and Research Conference Proceedings. Alabama, USA, 2003, pp. 2328-2362.

[3] JUVONEN, P., Effects of non-metallic inclusions on fatigue properties of calcium treated steels. PhD thesis, Helsinki University of Technology Espoo 2004.

[4] GHOSH, Ahindra. Secondary steelmaking. New York: CRC Press, 2001, p. 344.

[5] DOMMASCHK, Claudia. Metallurgical defects of cast steel. Freiberg: Publishing of the TU Bergakademie Freiberg Foundry Institute, 2012. p. 43.

[6] ZHANG, L., THOMAS, B.G., Inclusions in continuous casting of steel, XXIV National Steelmaking Symposium, Mexico, Mich, 2003, pp. 138-183.

[7] MERDER, Tomasz. Numerical and physical modelling of non-metallic inclusions distribution during the flow of liquid steel by cc tundish. Gliwice: Publishing of the Silesian University of Technology, 2018. p. 174.

[8] WARZECHA, M., HUTNY, A.M., MERDER, T., JĘDRYSIAK, B., Methodology of inclusions removing from steel flowing through the tundish. Metalurgija, 2016, vol. 56, no. 3-4, pp. 291-293.

[9] Information materials Meyerinst Leica DM IRM, 2018. Available from https://meyerinst.com.

[10] Information materials JVC TK-C1380, 2018. Available from https://cctvcentersl.com. 